\title{
Health Reform, Medicare for All, and Family Physicians
}

Joshua Freeman, MD

(Fam Med. 2020;52(3):165-7.)

doi: 10.22454/FamMed.2020.970445

$\mathbf{T}$ he US health care system is a mess. It has the worst outcomes, as well as the highest cost ${ }^{1,2}$ of all developed countries that are part of the Organization for Economic Cooperation and Development (OECD). If it sometimes has the best health care in the world for individuals to whom money is no object, as demonstrated by the foreign kings and princes who come here for certain procedures, it certainly does not when the health status and care of the population as a whole is considered.

The American people-all ages, ethnicities, genders, and political leanings-know this. Increasingly, health care, and more specifically the ability to access it, is cited as the number one or two domestic issue by Americans ${ }^{3-5}$ in poll after poll. Health care debt is the leading cause of personal bankruptcy.,7 The breadth of this concern is the reason for the increasing popularity of a single-payer health plan, or Medicare for All (MFA). While single-payer means that one entity (the government) pays for everyone's health care, actual health care delivery can be done, as it is now, by a variety of public and private providers. MFA is most prominently advocated by Democratic presidential candidates Senators Bernie Sanders (I-VT) and Elizabeth Warren (D-MA). It is much like the system in Canada, also called Medicare, and is based on the idea that the US Medicare program, now over 50 years old, has been a successful and cost-effective program for the people it covers, and that the simplest way to move to single payer is to expand Medicare to everyone.

Other Democratic candidates have advocated less ambitious plans, most built upon shoring up and expanding the coverage extended by the Affordable Care Act (ACA), commonly referred to as Obamacare. These include a variety of mixes of public and private coverage, "Medicare for More" (eg, those over 55 years of age), and other plans that do not seek complete restructuring of the health economy. Republicans have continued to talk about repealing Obamacare, presumably because of ideological opposition to increased government involvement, although they did not do so when they controlled both houses of Congress and the presidency. The impact of the ACA was limited by an early Supreme Court decision that allowed states to reject expansion of Medicaid, and recent court decisions have put other aspects of it, such as the individual mandate, in jeopardy. ${ }^{8}$

In this issue of Family Medicine, two commentaries address the issue of health reform. They are not a classic point-counterpoint, as neither truly advocates for Medicare for All and neither argues that the current system is not in need of great reform. However, they do raise different issues.

David S. Guzick questions whether the US health care industry can be improved without destroying it, and suggests that it can. ${ }^{9} \mathrm{He}$ notes that $90 \%$ of the population has health coverage, but that there is a need to both improve health outcomes and reduce cost, as well as to increase access for the other $10 \%$. He acknowledges that MFA would solve the problems of access, reduce administrative cost and pharmacy prices, and make it easier to implement cost-effectiveness analysis and evidencebased practice. But he expresses the concerns that because the federal government would control the whole health budget, it could slash funding, that the executive branch might make 
unreasonable or deleterious decisions about health care, and that there are insufficient resources to sustain funding for MFA (including for the increased demand resulting from people actually having adequate access). His suggestions for improvement include strategies to improve quality and reduce prescription drug and administrative costs.

In "Beyond Medicare for All," Lisa R. Chacko emphasizes the role of physicians, especially family physicians, and the multiplicity of opinions they have regarding changing the health care system. ${ }^{10}$ She also notes that the phrase "Medicare for All" could represent a variety of policy solutions with varying price tags and timelines for implementation, and suggests it is critical to have bipartisan appeal. In particular, she emphasizes the need to distinguish between how care is delivered and how it is financed, and cites several historical and current models being used by different states and localities that could be more broadly implemented nationally.

Both commentaries make important points that should be addressed by any health reform, including MFA. Dr Chacko's distinction between the financing and delivery systems is critical, as is Dr Guzick's emphasis on the need for improving health care quality, not just changing its financing. The MFA bills of 2019, S $1129,{ }^{11}$ sponsored by Senator Sanders, and HR $1384,{ }^{12}$ sponsored by Representative Pramila Jayapal (D-WA), both call for greatly expanded coverage and greater emphasis on quality and evidence. Just recently the American College of Physicians (ACP), the internists' organization and second-largest doctors group in the country, endorsed Medicare for All. ${ }^{13}$

There are, however, at least three major problems with any plan that does not comprehensively cover all Americans in the same single-payer plan. The first is financial: while the United States already spends much more on health care, measured in total or per capita, than any other OECD country (in most cases two to three times as much), not all of this is spent on actually delivering health care. A recent study in the Annals of Internal Medicine demonstrates that more than $30 \%$ of our entire health care expenditures are for administrative costs. ${ }^{14}$ Indeed, those who express concern about the cost of MFA are often the same people who advocate keeping a role for private insurance in health reform. If the administrative costs and profit inherent in having a private financing component are not seriously reduced or eliminated, there will be less funding for covering everyone.

The second issue impacts both concerns about quality and the potential for the federal government cutting funding (already a major problem with current programs like Medicaid and even potentially Medicare). The protection for both under MFA is that everyone is in the same program. If the well-educated, wealthy, and empowered are in the same health plan as those who are not, they will demand that it is adequately funded and works for them, which will benefit everyone. Any plan that allows segmentation of coverage by income, employment status, or demographic characteristics lacks this protection.

The most important issue, however, is ensuring good coverage for everyone and not leaving anyone out. While perhaps only $10 \%$ of Americans are uninsured, many more are underinsured and have inadequate coverage. The number of people affected by rising costs, including premiums, copays, deductibles, and coinsurance increases every year; these are not just numbers, they are real people with names. They are people like Blake Collie, an 8-year old with a cerebral aneurysm whose insurance, for which his parents paid all they could afford, would not cover treatment costs, urging them to "trust in God."15 Blake is not an isolated case. For the first time in decades, life expectancy in the United States has gone down for several years in a row, especially in the 25-64 year-old age group. ${ }^{16}$

But, while the uninsured and underinsured have names, those names are rarely those of the politicians, pundits, providers, and policy analysts who suggest that it is ok to have a hodgepodge of programs that cover most, but not all, people. These experts know that they themselves will not be the ones left out. Those who will be left out do not write policy pieces. I repeat a question I asked many years ago: When was the last time, even in private but certainly in public, you ever heard someone say, "I'm really suffering without health coverage, but don't worry about including me and my family in your health reform plan. We don't want to let the perfect be the enemy of the good?"

As family physicians we are bound to think about the health of all people, our patients, whatever their station in life. They all must be included in the way we fix our health system.

CORRESPONDENCE: Address correspondence to Dr Joshua Freeman at jfreeman@kumc.edu. 


\section{References}

1. Schneider EC, Sarnak DO, Squires D, Shah A, Doty MM Mirror, Mirror 2017: International Comparison Reflects Flaws and Opportunities for Better U.S. Health Care. The Commonwealth Fund. https://www.commonwealthfund.org/publications/fund-reports/2017/jul/mirror-mirror2017-international-comparison-reflects-flaws-and. Published Juley 14, 2017. Accessed February 4, 2020.

2. Freeman J. Health, Medicine and Justice: Designing a Fair and Equitable Healthcare System. Friday Harbor, WA: Copernicus Healthcare; 2015.

3. Kiley J. Most continue to say ensuring health care coverage is government's responsibility. Pew Research Center. FactTank: News in the Numbers. https://www.pewresearch.org/ fact-tank/2018/10/03/most-continue-to-say-ensuring-healthcare-coverage-is-governments-responsibility/. Published October 3, 2018. Accessed February 4, 2020.

4. Galvin G. Survey: Health Care, Poverty Are Top Political Motivators in Countries. US News and World Report. https://www.usnews.com/news/best-countries/articles/2018-10-17/health-care-1-of-few-issues-that-spur-political-engagement-in-countries-pew-survey-finds. Published October 17, 2018. Accessed February 4, 2020.

5. Greenwood M. Poll: Immigration overtakes health care as top issue for voters. The Hill. https://thehill.com/homenews/ campaign/451397-poll-immigration-overtakes-health-careas-top-issue-for-voters. Published July 2, 2019. Accessed February 4, 2020.

6. Hamel L, Norton M, Pollitz K, Levitt L, Claxton G, Brodie M. The Burden of Medical Debt: Results From the Kaiser Family Foundation/New York Times Medical Bills Survey. Kaiser Family Foundation. https://www.kff.org/report-section/the-burden-of-medical-debt-section-3-consequences-ofmedical-bill-problems/.Published January 5, 2016. Accessed February 4, 2020.

7. Hamel L, Munana C, Brodie M. Kaiser Family Foundation/ LA Times Survey of Adults With Employer-Sponsored Health Insurance. Kaiser Family Foundation. http:// files.kff.org/attachment/Report-KFF-LA-Times-Surveyof-Adults-with-Employer-Sponsored-Health-Insurance. Published May, 2019. Accessed February 4, 2020.
8. Sanger-Katz M. Trump Administration Says Obamacare Lawsuit Can Wait Until After the Election. The New York Times. https://www.nytimes.com/2020/01/10/upshot/ obamacare-lawsuit-delay-sought-trump-republicans.html. Published January 10, 2020. Accessed February 4, 2020.

9. Guzick DS. Can the US health care industry be improved without blowing it up? Fam Med. 2020;52(3):168-170.

10. Chacko LR. Beyond Medicare for All. Fam Med. 2020;52(3):171-173.

11. Bernie Sanders US Senator for Vermont. The Medicare for All Act of 2019. https://www.sanders.senate.gov/download/ medicare-for-all-2019-summary. Accessed February 4, 2020.

12. Pramila Jayapal Congresswoman for WA-07. Medicare for All Act of 2019. https://jayapal.house.gov/medicare-for-all/ medicare-for-all-act-of-2019/. Accessed February 4, 2020.

13. American College of Physicians. Better is Possible: ACP's Vision for the U.S. Health Care System. https://www.acponline.org/advocacy/where-we-stand/better-is-possible-acpsvision-for-the-us-health-care-system. Accessed February 4, 2020.

14. Himmelstein DU, Campbell T, Woolhandler S. Health Care Administrative Costs in the United States and Canada, 2017. Ann Intern Med. 2020;172:134-142.

15. Abelson R. It Looks Like Health Insurance, But It's Not. 'Just Trust God,' Buyers Are Told. The New York Times. https://www.nytimes.com/2020/01/02/health/christianhealth-care-insurance.html. Published Januar 2, 2020. Accessed February 4, 2020.

16. Woolf SH, Schoomaker H. Life Expectancy and Mortality Rates in the United States, 1959-2017. JAMA 2019;322(20):1996-2016.

\section{Family Medicine Seeks Assistant Editor}

Family Medicine, the official journal of the Society of Teachers of Family Medicine, is seeking an assistant editor. This volunteer position will report to the editor of Family Medicine.

The assistant editor must...

- have personal experience with research and scholarship.

- possess a sense of clear writing, style, organization, and presentation of information.

- demonstrate understanding of scientific methods, statistics, and other analytic methods, research and publishing ethics, and the peer-review process.

- have a desire to read manuscripts and work with authors and reviewers.

- demonstrate the ability to adhere to established timelines.

- be available for weekly phone conferences with the editorial team.

- attend the Editorial Board meeting held each year in conjunction with the Annual Spring Conference.

Applications must be submitted by email by April 1 and include the following materials:

- a cover letter highlighting interest and qualification for the position

- a current curriculum vitae, including applicant's publications

Send application by email to fmeditor@ohsu.edu with subject line: Family Medicine Assistant Editor Search. Questions? Contact John Saultz, MD, Family Medicine Editor, at fmeditor@ohsu.edu.

Published 10 times a year, Family Medicine publishes high-quality medical education research. The journal also publishes clinical research, articles about information technology, practice management, research methods, and essays and commentaries-all with relevance to family medicine and primary care education. Family Medicine is published online at https:/ /journals.stfm.org/familymedicine/. 